\title{
STUDI EKSPERIMENTAL PENGARUH BLOK-HALANG PADA LANTAI KOLAM OLAK BENDUNG TERHADAP PENGGERUSAN LOKAL
}

\author{
Robby Yussac Tallar ${ }^{(1)}$, Ivan ${ }^{(2)}$ \\ ${ }^{(1)}$ Dosen Program Studi S-1 Teknik Sipil, Fakultas Teknik, Universitas Kristen Maranatha \\ (2) Alumni Program Studi S-1 Teknik Sipil, Fakultas Teknik, Universitas Kristen Maranatha \\ Jalan Prof. Drg. Suria Sumantri No. 65, Bandung 40164 \\ e-mail: robbyyussac@yahoo.com
}

\begin{abstract}
ABSTRAK
Permasalahan penggerusan lokal yang terjadi di bagian hilir bendung merupakan fenomena nyata yang dihadapi suatu kontruksi bendung dan harus dicarikan solusinya. Berbagai upaya untuk mengurangi permasalahan penggerusan lokal telah diteliti dan dilakukan. Penyebab utama dari fenomena penggerusan lokal adalah akibat adanya perbedaan elevasi muka air antara hulu dan hilir dari suatu bendung, maka terjadi loncatan air yang mengakibatkan penggerusan lokal pada hilir bendung. Kolam olak adalah bagian dari konstruksi suatu bendung yang berfungi untuk mengurangi penggerusan lokal dengan cara meredam energi aliran air namun dalam kenyataannya masih kurang maksimal mengatasi penggerusan lokal yang terjadi. Oleh karena itu penelitian ini bertujuan untuk memodifikasi kolam olak dengan pemberian blok-halang sehingga diketahui pengaruh atau efektivitas dari blok-halang tersebut terhadap penggerusan lokal yang terjadi pada hilir bendung. Studi eksperimental dilakukan dengan menggunakan model fisik dua dimensi pada jenis bending tetap tipe gergaji dua gigi. Debit aliran yang digunakan dalam adalah 25\% Qmax, 50\% Qmax dan 100\% Qmax. Hasil penelitian menunjukkan bahwa dengan menggunakan blok-halang dengan dimensi $4 \mathrm{~cm} \times 4 \mathrm{~cm}$ dengan ketinggian $6 \mathrm{~cm}$ serta jarak antar blok-halang yaitu $4 \mathrm{~cm}$ dan jarak blok-halang ke ambang hilir yaitu 14,4cm pada lantai kolam olak bendung gergaji dua gigi dapat mengurangi kedalaman dan luas penggerusan lokal yang terjadi pada hilir bendung. Saran untuk penelitian kedepannya adalah penggunaan riprap sebagai material tambahan pada bagian hilir bendung.
\end{abstract}

Kata Kunci: Bendung gergaji dua gigi, blok-halang, kolam olak, loncatan air, penggerusan lokal

\begin{abstract}
The problem of local scouring that occurs in the lower reaches of the weir is a real phenomenon which is the construction of the weir and a solution must be sought. Various efforts to overcome the existing problems have been made and carried out. The main cause of the local scouring phenomenon is the difference elevation between the upstream and downstream of a weir, then there is waterflow jump which is carried out local scouring at the weir downstream. Energy dissipator is part of the construction of a weir that has a function to reduce local scouring by reducing the energy of the waterflow. However, it is not optimal enough to overcome the occured local scouring. Therefore, this study aims to improve the energy dissipator by providing blocks so that it is approved or used from these blocks for local scouring carried out at the weir downstream. An experimental study was carried out using a two-dimensional physical model on the two-teeth saw weir type. The flowrate used in is 25\% Qmax, 50\% Qmax and 100\% Qmax. The results showed by using blocks with dimensions of $4 \mathrm{~cm} x 4 \mathrm{~cm}$ with a height of $6 \mathrm{~cm}$ and the distance between the block blocks is $4 \mathrm{~cm}$ and the distance of the blocks to the downstream threshold of $14.4 \mathrm{~cm}$ on the floor of the energy dissipator can increase the depth and area of local scouring that occurs downstream of the weir. Suggestions for future research are the use of riprap as an additional material in the downstream part of the weir.
\end{abstract}

Keywords: Two-teeth saw weir type, blocks, energy dissipator, hydraulic jump, local scouring

Studi Eksperimental Pengaruh Blok-Halang pada Lantai Kolam Olak Bendung Terhadap Penggerusan Lokal (Robby Yussac Tallar dan Ivan) 


\section{Pendahuluan}

Penerapan bendung gergaji di Indonesia memang masih belum banyak, namun dapat ditemukan di beberapa wilayah yang relatif landai/datar. Secara umum, fungsi dari bendung gergaji sama dengan bendung tetap lainnya yaitu mengambil air yang dibutuhkan untuk keperluan irigasi dan melimpahkan air yang berlebih ke bagian hilir. Manfaat lain dari bendung gergaji antara alin dapat mengendalikan banjir yang terjadi di udik, menstabilkan fluktuasi muka air di udik pelimpah, menahan laju angkutan sedimen ke hilir, dan meninggikan dasar sungai. Adapun keunggulan dari bendung gergaji adalah menahan laju angkutan sedimen ke hilir, kapasitas limpahannya lebih besar dan perubahan elevasi muka air yang terjadi di udik lebih stabil dibanding dengan pelimpah lainnya akibat dari fluktuasi debit. Adanya perbedaan elevasi antara muka air pada udik dan hilir bendung gergaji maka akan terjadi fenomena loncatan air yang mengakibatkan adanya gerusan lokal dasar sungai di hilir bendung. Untuk mereduksi momentum aliran yang mana akan menurunkan kecepatan setelah terjadi loncatan air, maka dipasanglah blok-halang. Berdasarkan hal tersebut, penelitian ini dilakukan untuk mengetahui seberapa besar pengaruh atau efektivitas dari blok-halang dalam mengurangi penggerusan lokal yang terjadi pada hilir bendung.

\section{Tinjauan Pustaka}

\subsection{Pengertian Bendung dan Jenis-Jenis Bendung}

Bendung adalah suatu bangunan yang bertujuan untuk meninggikan taraf muka air untuk mendapatkan tinggi terjun yang diinginkan dan dibangun melintang sungai, sehingga air dapat dialirkan ke jaringan irigasi (KP-02, 1986). Bendung dapat juga diartikan sebagai suatu konstruksi bangunan air yang melintang sungai dan berfungsi untuk meninggikan taraf air sungai untuk kepentingan irigasi. Secara umum, bendung dapat dibagi menjadi bendung tetap dan bendung gerak. Disamping itu terdapat jenis bendung khusus seperti bendung karet, bendung gergaji dan bendung-bendung khusus lainnya yang memiliki fungsi masing-masing.

\subsection{Bendung Tipe Gergaji}

Bendung tipe gergaji memiliki fungsi utama untuk meninggikan taraf muka air, memberikan air ke bangunan pengambil sekaligus mengendalikan debit aliran sungai. Letak dari bendung gergaji dibuat bergerigi mirip gergaji yang berfungsi untuk memperpanjang lebar efektif pelimpah dengan meningkatkan kapasitas pelimpah. Dalam 
membangun bendung gergaji dibutuhkan syarat yang harus dipenuhi yaitu posisi bendung gergaji dibuat pada aliran sungai yang cenderung stabil, limpasan maksimum tidak terjadi, maupun tidak terkandung material material yang dibawa oleh aliran sungai (Departemen Permukiman dan Prasarana Wilayah, 2004). Berikut adalah denah dan potongan dari bendung tipe gergaji dapat dilihat pada Gambar 1.
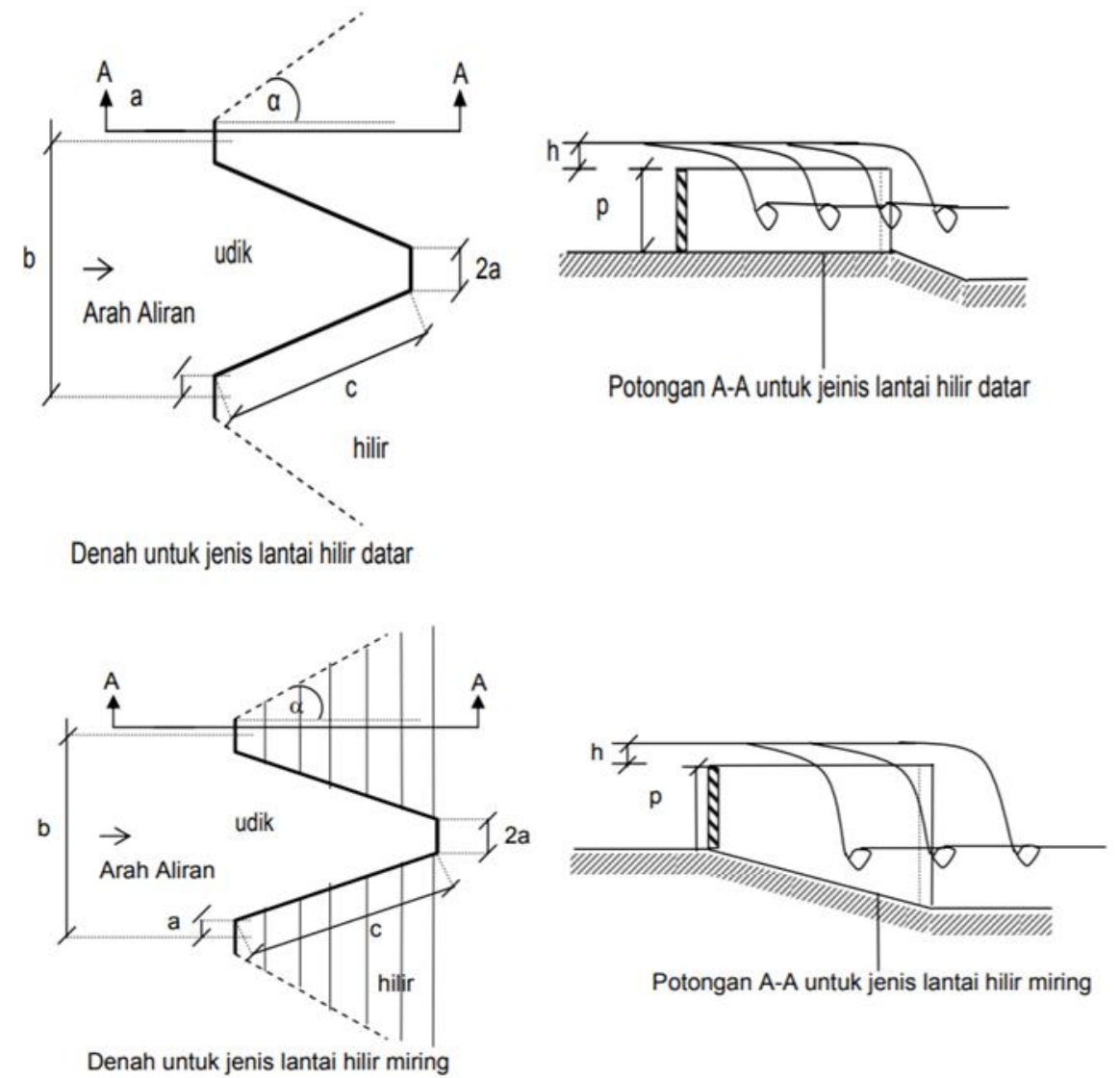

\section{Gambar 1. Potongan dan Denah Bendung Gergaji}

Sumber: Departemen Permukiman dan Prasarana Wilayah, 2004

Denah dan potongan bendung tipe gergaji pada Gambar 1 dapat dijelaskan sebagai berikut:

$\mathrm{a}=$ Setengah lebar ujung-ujung gigi gergaji pada bagian dinding $(\mathrm{m})$

$\mathrm{b}=$ Lebar satu buah gigi gergaji $(\mathrm{m})$

$\mathrm{c}=$ Panjang sisi gigi gergaji pada bagian dinding $(\mathrm{m})$

$\mathrm{h}=$ Tinggi tekan hidraulik dari muka air hulu diukur terhadap mercu bendung (m)

$\mathrm{p}=$ Ketinggian pembendungan $(\mathrm{m})$

Ig = Panjang satu gigi gergaji $(\mathrm{m})=4 \mathrm{a}+2 \mathrm{c}$ 
Bendung tipe gergaji terdiri atas tubuh bendung, mercu pelimpah, peredam energi, tembok sayap hulu dan hilir, bangunan bilas dan bangunan pengambil, bangunan penangkap sedimen, tembok pangkal, jembatan pelayanan serta jembatan pelayanan. Dimensi dari bentuk dan bangunan bendung tipe gergaji perlu memperhatikan hal sebagai berikut:

1. Letak dan bentuk gigi

a. Pada dasarnya, pelimpah yang berbentuk segitiga menghasilkan kapasitas pelimpah terbesar. tetapi, akibat bentuk segitiga maka dinding pelimpah pada ujung hulu dan hilir sangat peka terhadap efek muka air hilir dan akibat tumbukan aliran menyilang yang jatuh dari dinding pelimpah maka menyebabkan kehilangan aerasi. Proses ditambahkannya udara ke dalam air yang mana memberikan gelembung halus udara dan membiarkannya naik melalui air disebut aerasi.

b. Bentuk dasar dari pelimpah persegi panjang dapat mengakibatkan pengkonsentrasian aliran menuju pelimpah. Akibatnya, kapasitas pelimpah menurun dan dapat menimbulkan depresi pada muka air.

c. Pelimpah dengan bentuk dasar trapesium adalah pelimpah dengan efektivitas paling baik. Seperti terlihat pada Gambar 2 .

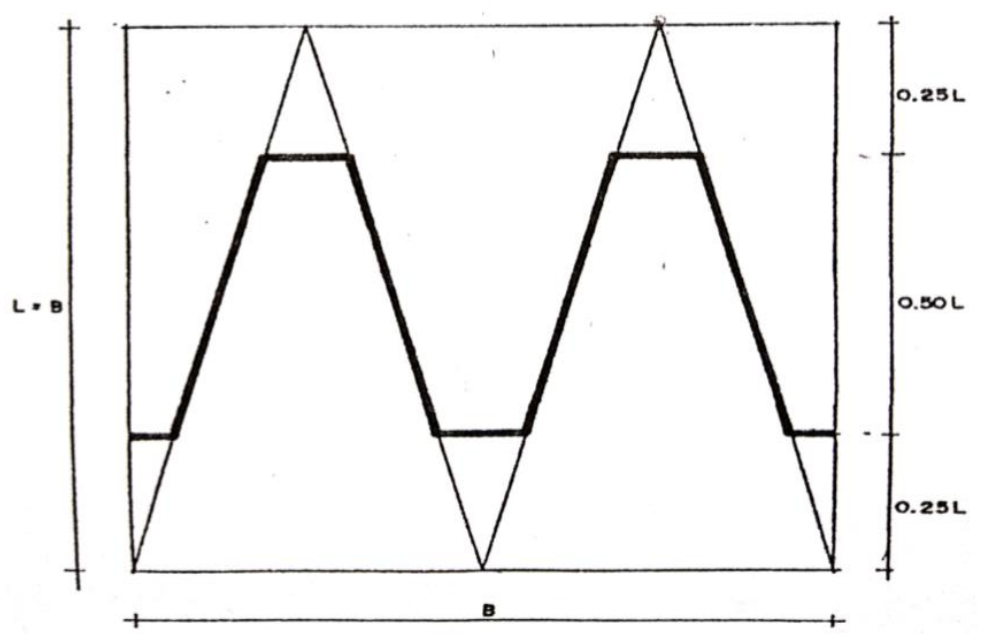

Gambar 2. Bentuk Optimal Bendung Gergaji

2. Pengaruh elevasi muka air hulu

a. Pelimpah gergaji merupakan pelimpah dengan kinerja paling baik $\frac{h}{p}$. 
b. Pada saat keadaan $\frac{h}{p}$ tinggi, debit dan kecepatan aliran yang besar dapat menyebabkan kontraksi air. Akibat dari kontraksi air ini maka dapat menyebabkan terjadinya tinggi dari tekanan sungai hulu pelimpah lebih tinggi daripada besar pelimpah bekerja dengan tinggi tekan aliran.

c. Berdasarkan pada karakteristik tersebut, maka maksimum dari tinggi muka air hulu adalah $\frac{h}{p} \leq 0,5$. Grafik dapat dilihat pada Gambar 3 .

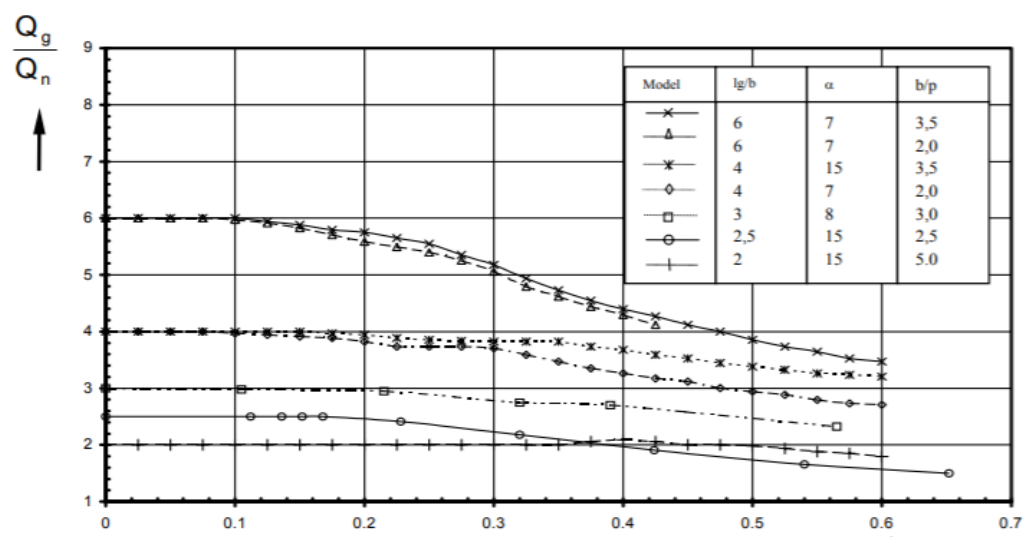

\section{Gambar 3. Pengaruh Kapasitas Pelimpah terhadap Tinggi Muka Air}

\section{Hulu}

Keterangan:

$\mathrm{n}$ = Jumlah "gigi" pelimpah gergaji.

$\frac{b}{p}=$ Perbandingan antara lebar satu gigi, b dengan tinggi bendung, $\mathrm{p}$.

$\frac{h}{p}=$ Perbandingan antara tinggi bendung diukur dari lantai hulu, $\mathrm{p}$ dengan tinggi tekan hidraulik, h.

$\frac{I g}{b}=$ Perbandingan antara panjang mercu pelimpah gergaji yang terbentuk.

$\underline{Q g}$

$\overline{Q n}=$ Nilai perbandingan besar debit pelimpah gergaji dibandingkan dengan besar debit pelimpahan dengan menggunakan pelimpah lurus biasa dengan lebar bentang yang sama. $\alpha \mathrm{i}=$ Sudut antara arah aliran utama air dengan sisi pelimpah.

Disamping hal-hal lainnya yang harus diperhatikan dalam perencanaan konstruksi bendung gergaji. 


\section{Metodologi Penelitian}

Metode yang digunakan pada penelitian ini adalah metode eksperimental dengan variasi percobaan atau skenario sebagai berikut:

a. Perbandingan setelah menggunakan blok-halang dan sebelum menggunakan blokhalang;

b. Debit yang digunakan adalah debit $25 \%$ dari debit maksimum, debit $50 \%$ dari maksimum dan debit $100 \%$ yang merupakan debit maksimum.

Model fisik yang digunakan dalam penelitian ini yaitu saluran terbuka dengan panjang 15,2 m, tinggi 0,64 m, lebar $1 \mathrm{~m}$. Blok-halang yang digunakan berdimensi $4 \mathrm{~cm}$ x $4 \mathrm{~cm}$ dengan ketinggian $6 \mathrm{~cm}$ dapat dilihat pada Gambar 3.2. Jumlah blok-halang yang akan dipasang yaitu 12 buah dengan jarak antar blok-halang yaitu $4 \mathrm{~cm}$. Blok- halang akan dipasang menerus sepanjang $1 \mathrm{~m}$ sesuai dengan lebar saluran. Jarak antara blok-halang dengan ambang ujung yaitu 14,4 cm sedangkan jarak antara blok-halang bagian tepi dengan dinding saluran yaitu masing-masing $0,25 \mathrm{~cm}$. Material yang digunakan untuk mendesain blok-halang yaitu berupa kayu.

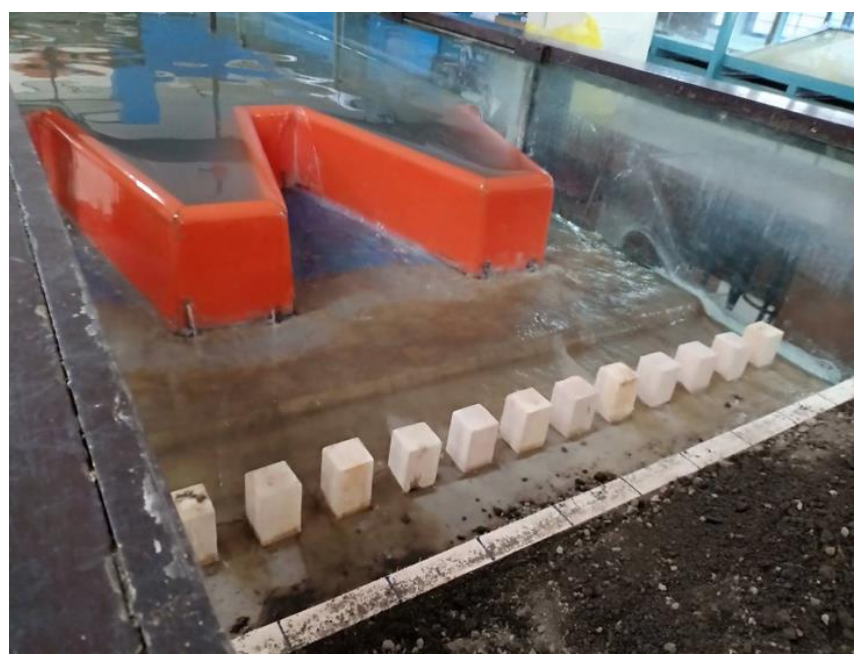

\section{Gambar 4. Tampak Depan Penempatan Blok-Halang}

\section{Hasil Analisis Data}

Pada penelitian ini menggunakan hipotesis awal yaitu dengan adanya blokhalang pada kolam olak bendung gergaji dapat mempengaruhi kecepatan aliran akibat loncatan air sehingga mengurangi penggerusan yang terjadi. Dari variabel yang telah ditentukan diperoleh 6 kontur, yaitu: 3 kontur yang menggunakan blokhalang dan 3 kontur tanpa blok-halang. Profil penggerusan terdalam yang berbeda 
variabel, yaitu: variabel debit 25\%, variabel debit 50\%, dan variabel debit $100 \%$. Datum yang digunakan adalah ketinggian pasir awal $30 \mathrm{~cm}$.

\subsection{Analisis Penggerusan di Hilir Bendung Gergaji Dua Gigi Tanpa Blok-Halang}

Untuk debit rencana 100\% tanpa menggunakan blok-halang pada kolam olak bendung gergaji dua gigi memperlihatkan hasil penggerusan yang terjadi di hilir bendung gergaji dua gigi dengan variabel debit $100 \%$ yang diperoleh setelah membaca elevasi muka air di meteran taraf di hulu bendung gergaji dua gigi dan mendapat penggerusan terdalam $-5 \mathrm{~cm}$. Untuk debit rencana 50\% tanpa menggunakan blok-halang pada kolam olak bendung gergaji dua gigi memperlihatkan hasil penggerusan yang terjadi di hilir bendung gergaji dua gigi dengan variabel debit 50\% yang diperoleh setelah membaca elevasi muka air di meteran taraf di hulu bendung gergaji dua gigi dan mendapat penggerusan terdalam $-3,5 \mathrm{~cm}$. Untuk debit rencana $25 \%$ tanpa menggunakan blokhalang pada kolam olak bendung gergaji dua gigi memperlihatkan hasil penggerusan yang terjadi di hilir bendung gergaji dua gigi dengan variabel debit 25\% yang diperoleh setelah membaca elevasi muka air di meteran taraf di hulu bendung gergaji dua gigi dan mendapat penggerusan terdalam $-2 \mathrm{~cm}$.

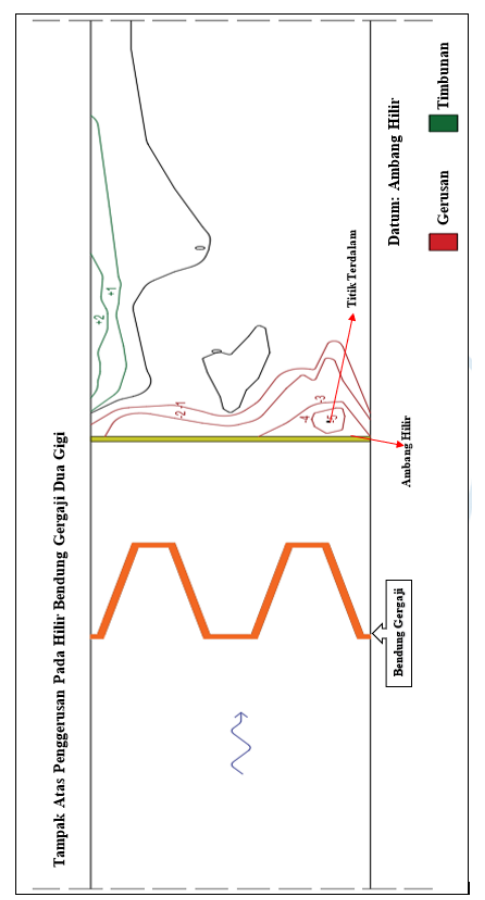

Gambar 5. Penggerusan di Hilir Bendung Gergaji Dua Gigi Tanpa Menggunakan Blok-Halang dengan Debit 100\% 


\subsection{Analisis Penggerusan di Hilir Bendung Gergaji Dua Gigi Dengan Blok- Halang}

Untuk debit rencana $100 \%$ dengan menggunakan blok-halang pada kolam olak bendung gergaji dua gigi memperlihatkan hasil penggerusan yang terjadi di hilir bendung gergaji dua gigi dengan variabel debit $100 \%$ yang diperoleh setelah membaca elevasi muka air di meteran taraf di hulu bendung gergaji dua gigi dan mendapat penggerusan terdalam $-4 \mathrm{~cm}$. Untuk debit rencana 50\% tanpa menggunakan blok-halang pada kolam olak bendung gergaji dua gigi memperlihatkan hasil penggerusan yang terjadi di hilir bendung gergaji dua gigi dengan variabel debit 50\% yang diperoleh setelah membaca elevasi muka air di meteran taraf di hulu bendung gergaji dua gigi dan mendapat penggerusan terdalam $-3 \mathrm{~cm}$. Untuk debit rencana $25 \%$ tanpa menggunakan blok-halang pada kolam olak bendung gergaji dua gigi memperlihatkan hasil penggerusan yang terjadi di hilir bendung gergaji dua gigi dengan variabel debit $25 \%$ yang diperoleh setelah membaca elevasi muka air di meteran taraf di hulu bendung gergaji dua gigi dan mendapat penggerusan terdalam $-2 \mathrm{~cm}$.

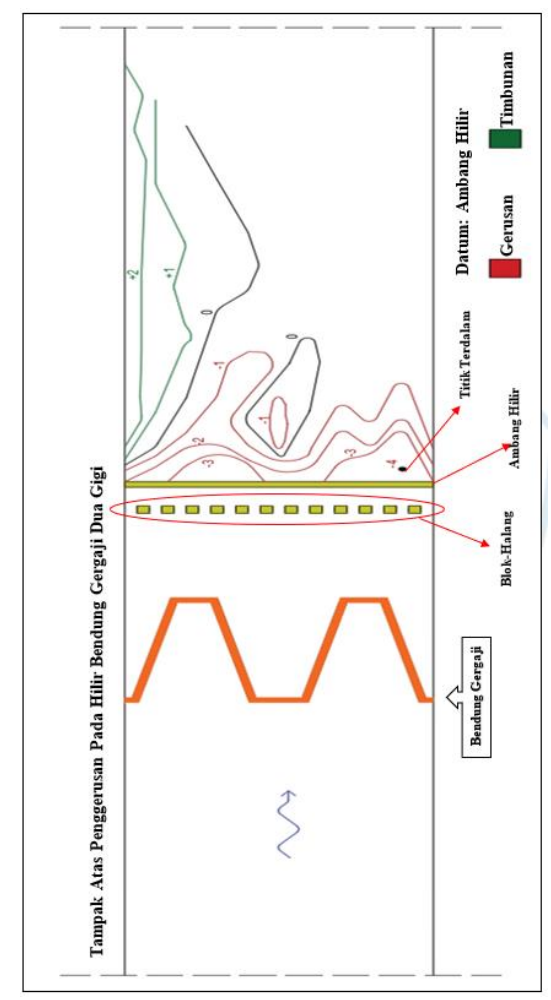

Gambar 6. Penggerusan di Hilir Bendung Gergaji Dua Gigi Menggunakan BlokHalang dengan Debit 100\% 


\section{Simpulan}

Dalam penelitian ini dapat disimpulkan antara lain penggerusan terdalam yang terjadi pada lantai kolam olak yang ditambahi blok-halang dengan debit 100\% sebesar -4 $\mathrm{cm}$, sedangkan yang tidak menggunakan blok-halang sebesar $-5 \mathrm{~cm}$. Hal ini menunjukan blok-halang efektif dalam meredam kecepatan aliran setelah terjadi loncatan air terhadap penggerusan yang terjadi. Untuk debit 50\% yang tanpa menggunakan blok-halang, penggerusan yang terjadi $-3,5 \mathrm{~cm}$ sedangkan yang menggunkan blok-halang penggerusannya lebih dangkal yaitu $-3 \mathrm{~cm}$. Hal ini berakibat pada daerah timbunan yang semakin kecil dengan adanya blok-halang yang efektif dalam meredam kecepatan aliran sehingga penggerusan lebih dangkal dan daerah timbunan lebih kecil. Pada debit 25\%, baik yang menggunakan blok-halang maupun yang tidak menggunakan blok-halang hasil yang didapatkan yaitu di hilir bendung gergaji dua gigi terjadi penggerusan sebesar $-2 \mathrm{~cm}$. Selain itu, blok-halang juga meratakan aliran air ke hilir dari bendung gergaji dua gigi sehingga timbunan yang terjadi lebih merata dibandingkan dengan yang tidak menggunakan blok-halang. Saran untuk penelitian kedepannya adalah penggunaan riprap sebagai material tambahan pada bagian hilir bendung.

\section{DAFTAR PUSTAKA}

1. Anggrahini, 2005, Hidrolika Saluran Terbuka. Penerbit Srikandi, Surabaya.

2. Chow, V.T., 1989, Open-Channel Hydraulic, Penerbit Erlangga, Bandung.

3. Departemen Pekerjaan Umum, 1986, Standar Perencanaan Irigasi, Kriteria Perencanaan, Bagian Bangunan Utama KP-02, Direktorat Jendral Pengairan, Jakarta.

4. Departemen Pekerjaan Umum, 1986, Standar Perencanaan Irigasi, Kriteria Perencanaan, Bagian Bangunan Utama KP-04, Direktorat Jenderal Pengairan, Jakarta.

5. Departemen Permukiman dan Prasarana Wilayah, Pd T-01-2004-A, Perencanaan Hidraulik Bendung dan Pelimpah Bendung Tipe Gergaji, Pedoman Konstruksi dan Bangunan.

6. Kamiana, I. M., 2018, Hidraulika, Penerbit TEKNOSAIN, Palang Karaya. 